\title{
microRNA expression pattern and its alteration following celecoxib intervention in human colorectal cancer
}

\author{
WEI CHANG CHEN ${ }^{1 *}$, MAO SONG LIN ${ }^{2 *}$, YU LAN YE ${ }^{1}$, HENG JUN GAO ${ }^{3,4}$, \\ ZHEN YUN SONG ${ }^{4}$ and XIAO YING SHEN ${ }^{4}$ \\ ${ }^{1}$ Department of Gastroenterology, The First Affiliated Hospital of Soochow University, Jiangsu 215006; \\ ${ }^{2}$ Department of Gastroenterology, Taizhou People's Hospital, Jiangsu 225300; \\ ${ }^{3}$ Institute of Digestive Disease, Tongji Hospital Affiliated to Tongji University, Shanghai 200065; \\ ${ }^{4}$ National Engineering Center for Biochip Design and Engineering, Shanghai 201203, P.R. China
}

Received October 6, 2011; Accepted February 13, 2012

DOI: 10.3892/etm.2012.531

\begin{abstract}
Accumulating evidence suggests that aberrant expression of microRNAs (miRNAs) is involved in several diseases, including cancer. This study aimed to investigate the miRNA expression pattern and its alteration following celecoxib intervention for human colorectal cancer (CRC). The miRNA expression profiles of CRC tissues, matched adjacent normal colorectal mucosae and HT-29 cells treated with celecoxib were determined using miRNA microarray, and further confirmed using the quantitative reverse transcription-polymerase chain reaction (Q-RT-PCR). The target genes of the aberrant miRNAs in HT-29 cells treated with celecoxib were further assessed through bioinformatic analysis. Results from this study demonstrated a significant increase in the expression of 35 miRNAs and a decrease in 30 miRNAs in the carcinoma tissues compared to the normal tissues $(\mathrm{P}<0.001)$. Of the 28 aberrantly expressed miRNAs, 20 were upregulated and 8 were downregulated in the HT-29 cells treated with celecoxib compared to the matched control cells $(\mathrm{P}<0.01)$. Furthermore, miR-552 was found to be correlated with clinical stage, lymph node and distant metastases $(\mathrm{P}<0.05)$. Stage and distant metastases revealed differential expression of miR-139-3p and grade disclosed aberrant expression of miR-142-3p. In addition, multiple target genes involved in several essential survival pathways were found be modulated by the aberrantly expressed miRNAs in HT-29 cells treated with celecoxib. Our data revealed that a common pattern of miRNA expression in the colorectum could distinguish malig-
\end{abstract}

Correspondence to: Professor Wei Chang Chen, Department of Gastroenterology, The First Affiliated Hospital of Soochow University, 96 Shizhi Street, Suzhou 215006, Jiangsu, P.R. China E-mail: weichangchen@126.com

*Contributed equally

Key words: microRNA, microarray, RT-PCR, colorectal cancer, celecoxib nant tissue from normal mucosa. Celecoxib inhibited HT-29 cell growth in vitro which was partly attributable to the altered expression of miRNAs. miRNAs may be involved in CRC tumorigenesis and can serve as potential therapeutic targets.

\section{Introduction}

Colorectal cancer (CRC) is one of the most common types of malignant neoplasm in developed countries and the incidence of CRC has increased in China due to the adoption of a Western lifestyle. Previous studies have demonstrated that several aberrant genes, including APC, $\beta$-catenin, K-Ras and certain MMR genes, are involved in carcinogenesis of the colorectum (1-3). However, at present, few molecules are considered as biomarkers able to differentiate early malignant CRC from normal tissue.

A new class of non-coding RNAs, known as microRNAs (miRNAs), was recently discovered and have been demonstrated to be involved in various human diseases, including cancer, through the regulation of target gene expression at the post-transcriptional level (4). miRNAs are 19- to 25-nt molecules cleaved from 70 - to 100 -nt hairpin pre-miRNA precursors generated from primary transcript miRNAs in the nucleus. The precursor is cleaved by the cytoplasmic RNase III, Dicer, into a 22-nt miRNA duplex; one strand of short-lived duplex is degraded, while the other strand, which serves as the mature miRNA, is incorporated into the RNA-induced silencing complex (RISC), and drives the selection of target mRNAs containing antisense sequences (5). Previous studies have indicated that over $30 \%$ of mRNAs in the mammalian genome may be regulated by individual miRNAs (6). However, only a small number of target mRNAs have been identified. The first evidence for miRNA involvement in human cancer was demonstrated by Calin et al in 2002 (7). Since then, the carcinogenic role of miRNAs has been identified not only in malignant hematopoietic disease, but also in solid tumors $(8,9)$. Several miRNA expression signatures have been recently reported in CRC (10-12). However, due to the different study procedures and samples, the definite miRNAs associated with CRC pathogenesis remain largely unknown. 
Celecoxib, an inhibitor of cyclooxygenase-2 (COX-2), may prevent $\mathrm{CRC}$, and even prohibits the growth of tumor cells, through the inhibition of angiogenesis, apoptosis and blockage of the cell cycle (13-15). However, to date, its exact anti-cancer mechanism in malignant neoplasms, including CRC, is poorly understood. To our knowledge, few studies have focused on the pathological role of miRNAs in the process of celecoxib treatment of CRC cells.

Recently, with the development of miRNA microarray technologies, expression profiling studies have been conducted which recognize miRNAs differentially expressed between normal and tumor samples, and identify cancer-specific miRNA signatures associated with well-defined clinicopathological features $(16,17)$. In this study, we present the results of genome-wide miRNA expression profiles of a set of CRC and normal colorectal tissues, in order to reveal the specific miRNAs correlated with CRC. Furthermore, the miRNA expression profiles of HT-29 cells before and after intervention with celecoxib were also determined in order to investigate the underlying role of miRNAs.

\section{Materials and methods}

CRC samples and cell line. With the approval of the Institutional Review Board of the First Hospital Affiliated to Soochow University, malignant colorectal tissues were obtained from patients undergoing colorectal resection for CRC. The matchpaired normal colorectal mucosae were obtained from the colorectum more than $5 \mathrm{~cm}$ away from the carcinoma tissue site in these patients, whose histology was confirmed using H\&E staining concurrently with the carcinoma tissues. Written informed consent was obtained from all patients according to the guidelines approved by the Institutional Research Board. All tissue samples were collected and immediately snap-frozen in liquid nitrogen, and stored at $-80^{\circ} \mathrm{C}$ until RNA extraction. The clinicopathological characteristics of the CRC patients are shown in Table I. The exclusion criteria included a previous history of local or systemic treatment for CRC.

The HT-29 cells were maintained in McCoy's 5A modified medium (Gibco-BRL, USA) supplemented with $10 \%$ fetal bovine serum (FBS; Sigma, USA). The cultures were incubated at $37^{\circ} \mathrm{C}$ in a humidified $5 \% \mathrm{CO}_{2}$ incubator. Celecoxib was obtained from Sigma and dissolved in dimethyl sulfoxide (DMSO) with a final concentration of $0.1 \%$ DMSO in the culture medium. The HT-29 cells were separated into eight groups, including the control (cells without intervention), DMSO (cells treated with the same dose of DMSO as the control group) and celecoxib groups treated with concentrations 50-350 $\mu \mathrm{mol} / 1$. Cells in each group were seeded at $1 \times 10^{4}$ cells per well in a 96-well culture plate. Twenty-four hours later, each well was incubated with DMSO or celecoxib at different concentrations for 24, 48 or $72 \mathrm{~h}$. Cell viability in 96-well plates was evaluated using the Cell Counting Kit 8 (CCK-8) assay.

RNA extraction and miRNA array analysis. Total RNAs from 6 human CRCs and 6 paired normal colorectal tissues and 2 groups of HT-29 cells (control group and cells treated with $237.73 \mu \mathrm{mol} / 1$ celecoxib for $48 \mathrm{~h}$ ) were analyzed by miRNA microarray. Total RNA isolation was conducted with TRIzol (Invitrogen, Carlsbad, CA, USA) according to the manufac-
Table I. Clinicopathological data of 25 colorectal cancer patients.

\begin{tabular}{|c|c|}
\hline Characteristics & $\begin{array}{l}\text { No. of cases } \\
\quad(n=25)\end{array}$ \\
\hline \multicolumn{2}{|l|}{ Age (years) } \\
\hline Median & 63 \\
\hline Range & $43-83$ \\
\hline \multicolumn{2}{|l|}{ Gender } \\
\hline Male & 6 \\
\hline Female & 19 \\
\hline \multicolumn{2}{|l|}{ Tumor size (cm) } \\
\hline$\geq 5$ & 14 \\
\hline$<5$ & 11 \\
\hline \multicolumn{2}{|c|}{ Depth of tumor invasion ${ }^{a}$} \\
\hline Serosa & 19 \\
\hline Mucosa & 6 \\
\hline \multicolumn{2}{|l|}{ Histological type } \\
\hline High & 1 \\
\hline Moderate & 19 \\
\hline Poor & 5 \\
\hline \multicolumn{2}{|c|}{ Lymphatic invasion } \\
\hline$(-)$ & 15 \\
\hline$(+)$ & 10 \\
\hline \multicolumn{2}{|l|}{ Liver metastasis } \\
\hline$(-)$ & 20 \\
\hline$(+)$ & 5 \\
\hline \multicolumn{2}{|l|}{ Clinical stage ${ }^{\mathrm{b}}$} \\
\hline I & 5 \\
\hline II & 8 \\
\hline III & 7 \\
\hline IV & 5 \\
\hline
\end{tabular}

anvasive depth of the tumor (serosa, tumor invasion to the seroma; mucosa, tumor invasion to the mucosa). ${ }^{\mathrm{b}} \mathrm{TNM}$ stage system formulated by AJCC/NCCN (2009) according to tumor size, lymph node involvement and distant metastasis.

turer's instructions. The concentration and purity of the total RNAs were assessed using a spectrophotometer, and RNA integrity was verified using an Eppendorf Biophotometer (Eppendorf, Germany). RNA labeling and hybridization on miRNA microarray chips were conducted according to the miRNA expression profiling assay guide (Illumina, USA). The assay was initiated by polyadenylating $200 \mathrm{ng}$ of total RNA with a poly-A polymerase enzyme (PAP). The polyadenylated RNA was then converted to cDNA using a biotinylated oligo-dT primer with a universal PCR sequence at its $5^{\prime}$-end. Following PCR amplification, the labeled, single-stranded product was hybridized to Illumina miRNA microarrays, which contained probes for 1146 human miRNAs representing a majority of known miRNAs (described in the Sanger Institute's miRBase database, Release 12.018), plus additional novel content derived using Illumina sequencing technology 
Table II. Inhibitory effect of celecoxib on the growth of HT-29 cells ( $n=3$, mean \pm SD).

\begin{tabular}{lcccc}
\hline Groups $^{\mathrm{a}}$ & \multicolumn{3}{c}{ Inhibitory rate at variable times $(\%)^{\mathrm{b}}$} \\
\cline { 2 - 5 } & $0 \mathrm{~h}$ & $24 \mathrm{~h}$ & $48 \mathrm{~h}$ \\
\hline Negative control & 0 & 0 & 0 & 0 \\
DMSO control & 0 & 0 & & \\
Celecoxib groups & & & $2.53 \pm 1.02$ & \\
$50 \mu \mathrm{mol} / 1$ & 0 & $2.01 \pm 0.78$ & $9.50 \pm 0.98$ & \\
$100 \mu \mathrm{mol} / 1$ & 0 & $4.76 \pm 1.37$ & $17.64 \pm 1.05$ & $20.17 \pm 2.01$ \\
$150 \mu \mathrm{mol} / 1$ & 0 & $7.43 \pm 0.65$ & $44.08 \pm 1.01$ & $43.47 \pm 1.45$ \\
$200 \mu \mathrm{mol} / 1$ & 0 & $29.43 \pm 0.74$ & $58.11 \pm 0.23$ & $64.06 \pm 1.21$ \\
$250 \mu \mathrm{mol} / 1$ & 0 & $40.22 \pm 0.24$ & $62.77 \pm 1.86$ & $82.07 \pm 0.98$
\end{tabular}

${ }^{a}$ HT-29 cells were divided into 8 groups, including negative and DMSO control groups and 6 groups treated with variable concentrations $(50-300 \mu \mathrm{mol} / \mathrm{l})$ of celecoxib. ${ }^{\mathrm{b}}$ Statistically significant when compared between the groups or the variable times by ANOVA and LSD (P<0.05). DMSO, dimethyl sulfoxide; ANOVA, analysis of variance; SD, standard deviation.

for $14 \mathrm{~h}$ at $45^{\circ} \mathrm{C}$. The microarrays were then washed using Illumina-prepared buffers. The Illumina iScan System (Illumina, USA) was further used to measure the fluorescence intensity at each addressed bead location. Normalization was performed using the average normalization method. The intensity of each hybridization signal was evaluated using Feature Extraction Software. The average values of the replicate spots of each miRNA were background subtracted, normalized and subjected to further analysis.

Quantitative real-time polymerase chain reaction (Q-RT-PCR). For miR-552, miR-142-3p, miR-139-3p, miR133b, miR-26a-1*, miR-142-5P and RNU6B (internal control) specific cDNA synthesis was conducted using an miScript Reverse Transcription kit (Qiagen, Hilden, Germany) according to the manufacturer's instructions. Q-RT-PCR was performed using an miScript SYBR Green PCR kit (Qiagen). The reactions were incubated in a 96-well optical plate for $15 \mathrm{~min}$ at $95^{\circ} \mathrm{C}$ followed by 40 cycles of $5 \mathrm{sec}$ at $95^{\circ} \mathrm{C}, 31 \mathrm{sec}$ at $61^{\circ} \mathrm{C}$ and then were held constant at $4^{\circ} \mathrm{C}$. Expression analysis was performed in triplicate for each sample. A melting curve analysis and agarose gel electrophoresis were conducted to confirm the specificity of the amplification reactions. The U6 small nuclear RNA was used as the normalization control. The miRNA expression level was quantified using the ABI Prism 7300 Sequence Detection System (Applied Biosystems, Foster City, CA, USA). The relative expression of each miRNA was calculated using the $2^{-\Delta \Delta \mathrm{Ct}}$ method, with the ratio of the median expression sample among all the cancer and paired normal tissue samples used as the calibrator.

miRNA target functional analysis through enrichment analysis and GeneGo pathway annotation based on miRNA expression profiles in HT-29 cells following celecoxib treatment. According to the results from the bioinformatic techniques, the target genes of the deregulated miRNAs in the HT-29 cells following intervention of celecoxib compared to HT-29 cells without treatment were selected based on three miRNA target gene prediction software databases (miRNAs, RNAHybrid and Targetscan). Furthermore, enrichment analysis was applied in order to organize the target genes into three categories, including common, similar and unique, and in order to match them to functional pathways in the MetaCore gene pool evaluated with the P-value. The smaller the P-value, the greater possibility that the target gene is in a certain pathway. Meanwhile, the target genes of the aberrant miRNAs were collected, and subjected to GeneGo pathway annotation. We chose to illustrate only pathways that had $\mathrm{P}<0.001$.

Statistical analysis. All results are expressed as mean \pm standard deviation (SD). Statistical analysis was conducted using the Student's t-test for the comparison of the cancer group and the normal tissues in the microarray analysis; $\mathrm{P}<0.001$ was considered to indicate a statistically significant difference. The Illumina custom error model was used to analyse the differences in expression between the HT-29 cells treated with celecoxib and non-treated cells; P-value $<0.01$ was considered to indicate a statistically significant difference. Analysis of variance (ANOVA) was used to compare the expression of selected aberrant miRNAs as determined by the Q-RT-PCR assay. Using RT-PCR analysis, an miRNA was designated as overexpressed if the expression was $>2.0$-fold, and underexpressed if the expression was $<0.5$-fold when compared to 10 paired normal tissues in all 25 clinical CRC samples and two different groups of HT-29 cells. P-value $<0.05$ was considered to indicate a statistically significant difference, and was calculated using SPSS software 16.0 (SPSS, Chicago, IL, USA).

\section{Results}

Celecoxib induces growth arrest in HT-29 cells. We first examined the effect of celecoxib on the growth of HT-29 cells. All cells were treated with different concentrations of 
Table III. Aberrantly expressed miRNAs in colorectal cancer compared with paired normal samples.

\begin{tabular}{|c|c|c|c|}
\hline miRNAs & P-value & FDR & Fold difference \\
\hline \multicolumn{4}{|c|}{ Upregulated miRNAs } \\
\hline hsa-miR-552 & 0.0007325 & 0.0083292 & 30.991 \\
\hline solexa-2580-353 & 0.0000681 & 0.0022763 & 25.040 \\
\hline hsa-miR-96 & 0.0000856 & 0.0023462 & 17.273 \\
\hline hsa-miR-592 & 0.0002807 & 0.0047352 & 14.624 \\
\hline hsa-miR-549 & 0.0000388 & 0.0021269 & 9.075 \\
\hline hsa-miR-452*:9.1 & 0.0000694 & 0.0022763 & 8.779 \\
\hline solexa-3277-272 & 0.0000129 & 0.0011112 & 8.395 \\
\hline hsa-miR-622 & 0.0000826 & 0.0023462 & 8.090 \\
\hline hsa-miR-142-5p & 0.0002650 & 0.0047352 & 7.886 \\
\hline hsa-miR-183* & 0.0000633 & 0.0022763 & 7.467 \\
\hline hsa-miR-31 & 0.0006344 & 0.0082695 & 7.218 \\
\hline hsa-miR-183 & 0.0007148 & 0.0083292 & 6.667 \\
\hline hsa-miR-135b & 0.0008084 & 0.0085520 & 6.351 \\
\hline hsa-miR-431 & 0.0000003 & 0.0000904 & 6.270 \\
\hline hsa-miR-142-3p & 0.0002952 & 0.0048110 & 5.975 \\
\hline hsa-miR-219-5p & 0.0004407 & 0.0063272 & 5.966 \\
\hline hsa-miR-660 & 0.0001536 & 0.0033122 & 5.569 \\
\hline hsa-miR-21* & 0.0000175 & 0.0013191 & 5.019 \\
\hline hsa-miR-452 & 0.0001538 & 0.0033122 & 4.964 \\
\hline hsa-miR-154* & 0.0001741 & 0.0034994 & 4.535 \\
\hline hsa-miR-16-1* & 0.0003140 & 0.0049827 & 4.495 \\
\hline hsa-miR-182* & 0.0008058 & 0.0085520 & 4.054 \\
\hline hsa-miR-335 & 0.0001095 & 0.0027512 & 3.963 \\
\hline hsa-miR-32 & 0.0006454 & 0.0082695 & 3.947 \\
\hline hsa-miR-337-5p & 0.0001608 & 0.0033435 & 3.904 \\
\hline hsa-miR-17* & 0.0006857 & 0.0082695 & 3.782 \\
\hline hsa-miR-801:9.1 & 0.0008589 & 0.0087782 & 3.461 \\
\hline HS_48.1 & 0.0008559 & 0.0087782 & 3.416 \\
\hline hsa-miR-584 & 0.0009022 & 0.0090124 & 3.242 \\
\hline hsa-miR-493 & 0.0000688 & 0.0022763 & 3.191 \\
\hline hsa-miR-494 & 0.0000451 & 0.0022663 & 3.177 \\
\hline hsa-miR-376c & 0.0009386 & 0.0091286 & 3.034 \\
\hline hsa-miR-221* & 0.0006731 & 0.0082695 & 2.856 \\
\hline hsa-miR-501-5p & 0.0007310 & 0.0083292 & 2.767 \\
\hline hsa-miR-376* & 0.0009989 & 0.0092487 & 2.293 \\
\hline \multicolumn{4}{|c|}{ Downregulated miRNAs } \\
\hline hsa-miR-145* & 0.0007459 & 0.0083292 & 0.372 \\
\hline hsa-miR-571 & 0.0009117 & 0.0090124 & 0.348 \\
\hline hsa-miR-29b-2* & 0.0002152 & 0.0041860 & 0.329 \\
\hline hsa-miR-328 & 0.0003520 & 0.0054425 & 0.321 \\
\hline hsa-miR-766 & 0.0005702 & 0.0076407 & 0.311 \\
\hline hsa-miR-195* & 0.0004025 & 0.0059197 & 0.279 \\
\hline hsa-miR-9* & 0.0002684 & 0.0047352 & 0.265 \\
\hline hsa-miR-30c- $2^{*}$ & 0.0003862 & 0.0058220 & 0.263 \\
\hline hsa-miR-1272 & 0.0002412 & 0.0045451 & 0.238 \\
\hline hsa-miR-1270 & 0.0009629 & 0.0092163 & 0.229 \\
\hline hsa-miR-363 & 0.0009986 & 0.0092487 & 0.229 \\
\hline hsa-miR-138-1* & 0.0004803 & 0.0065823 & 0.215 \\
\hline hsa-miR-20b & 0.0008063 & 0.0085520 & 0.212 \\
\hline hsa-miR-597 & 0.0002827 & 0.0047352 & 0.200 \\
\hline hsa-miR-30a* & 0.0000755 & 0.0022763 & 0.195 \\
\hline hsa-miR-9 & 0.0006589 & 0.0082695 & 0.180 \\
\hline HS_182.1 & 0.0000926 & 0.0024277 & 0.163 \\
\hline solexa-3695-237 & 0.0000065 & 0.0008341 & 0.159 \\
\hline hsa-miR-885-5p & 0.0000755 & 0.0022763 & 0.146 \\
\hline
\end{tabular}


Table III. Continued.

\begin{tabular}{lccc}
\hline miRNAs & P-value & FDR & Fold difference \\
\hline hsa-miR-133a & 0.0001340 & 0.0032321 & 0.134 \\
HS_132.1 & 0.0001420 & 0.0032933 & 0.133 \\
hsa-miR-139-3p & 0.0000612 & 0.0022763 & 0.129 \\
hsa-miR-504 & 0.0000633 & 0.0022763 & 0.119 \\
hsa-miR-129* & 0.0000233 & 0.0015611 & 0.091 \\
hsa-miR-383 & 0.0000259 & 0.0015618 & 0.073 \\
hsa-miR-1 & 0.0004601 & 0.0064521 & 0.049 \\
hsa-miR-133b & 0.0000082 & 0.0008341 & 0.044 \\
hsa-miR-187 & 0.0000083 & 0.0008341 & 0.030 \\
hsa-miR-490-5p & 0.0000012 & 0.0002412 & 0.019 \\
hsa-miR-490-3p & 0.0000002 & 0.0000904 & 0.015 \\
\hline
\end{tabular}

P-values reported are the result of the comparison analysis of miRNA expression patterns from 6 pairs of colorectal cancer and paired normal tissues using the Student's t-test. FDR is calculated by the Student's t-test analysis. FDR $0.5 \%$ predicts that this list is $99.5 \%$ accurate. miRNA, microRNA; FDR, false discovery rate.

Table IV. Aberrantly expressed miRNAs in HT-29 cells exposed to celecoxib campared with the control group ${ }^{\mathrm{a}}$.

\begin{tabular}{lc}
\hline miRNAs & Fold difference $^{\text {b }}$ \\
\hline Upregulated miRNAs & \\
HS_188 & 2.92 \\
HS_203 & 2.34 \\
HS_22.1 & 2.21 \\
HS_243.1 & 2.74 \\
HS_43.1 & 2.24 \\
hsa-let-7f-1* & 2.44 \\
hsa-let-7i* & 4.62 \\
hsa-miR-129-3p & 3.54 \\
hsa-miR-1303 & 2.44 \\
hsa-miR-141 & 3.37 \\
hsa-miR-142-5p & 5.33 \\
hsa-miR-301a & 2.11 \\
hsa-miR-30c-1* & 2.71 \\
hsa-miR-33b & 2.38 \\
hsa-miR-570 & 2.25 \\
hsa-miR-647 & 2.98 \\
hsa-miR-886-3p & 2.58 \\
solexa-2526-361 & 2.33 \\
solexa-499-2217 & 2.42 \\
solexa-826-1288 & 4.08 \\
Downregulated miRNAs & \\
HS_58 & \\
hsa-miR-1244 & 0.39 \\
hsa-miR-1268 & 0.20 \\
hsa-miR-26a-1* & 0.35 \\
hsa-miR-552 & 0.38 \\
hsa-miR-622 & 0.47 \\
solexa-3044-295 & 0.43 \\
solexa-603-1846 & 0.25 \\
\hline & \\
\hline
\end{tabular}

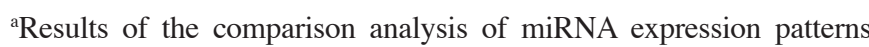
between HT-29 cells treated with celecoxib and the control group using Illumina custom error model analysis. ${ }^{b}$ Fold difference $>2$ indicates upregulation, while fold difference $<0.5$ indicates downregulation. celecoxib (0-300 $\mu \mathrm{mol} / \mathrm{l})$ for 24,48 and $72 \mathrm{~h}$ in the absence of FBS in the culture medium. The CKK- 8 assay demonstrated that upon the increase in concentration of celecoxib and treatment time, the inhibitory effect of celecoxib on HT-29 cells gradually increased. Celecoxib $(300 \mu \mathrm{mol} / \mathrm{l})$ demonstrated the greatest inhibitory effect with a 72-h survival rate of only $19.72 \%$. The results summarized in Table II further suggest that celecoxib suppresses the HT-29 cell growth in a time- and dose-dependent manner. According to the dose-effect curves, the $50 \%$ inhibition concentration $\left(\mathrm{IC}_{50}\right)$ of celecoxib in HT-29 cells at $48 \mathrm{~h}$ was $237.73 \pm 1.65 \mu \mathrm{mol} / 1$.

miRNA expression in CRC and normal colorectal tissues and alteration in HT-29 cells treated with celecoxib. An Illumina microarray platform containing 1146 probes was used to evaluate the miRNA expression profiles of the colorectal tissues, including 6 CRCs, 6 matched normal colorectal mucosae and 2 groups of HT-29 cells either treated or untreated with celecoxib. The microarray analysis demonstrated that miRNAs were differentially expressed between the CRCs and the normal tissues. The analysis identified that 35 miRNAs were upregulated and 30 were downregulated in the cancer tissues compared with their matched benign mucosa tissues $(\mathrm{P}<0.001)$ (Table III). When the HT-29 cells exposed to celecoxib were compared with the untreated cells, 20 miRNAs were found to be overexpressed while 8 miRNAs were underexpressed $(\mathrm{P}<0.01)$ (Table IV).

Validation of the microarray data by miRNA RT-PCR analysis. To confirm the results from the microarray analysis, the expression levels of miR-552, miR-142-3p, miR-139-3p and miR-133b (the novel and major miRNAs of particular interest in the CRC of these specimens identified in the microarray study described above) were measured using Q-RT-PCR in all 25 CRC cases and 10 normal colorectal mucosae (Table V). The major deregulated miRNAs, miR-26a-1* and miR-142-5p, in the HT-29 cells treated with celecoxib were also confirmed using the same method. As expected, a statistically significant upregulation in the expression of miR-552 and miR-142-3p 
Table V. Verification of the expression of various miRNAs using Q-RT-PCR.

miRNA expression level $(\text { mean } \pm \mathrm{SD})^{\mathrm{a}}$

\begin{tabular}{lrr}
\cline { 2 - 3 } miRNA & Colorectal cancer & Normal tissue \\
\hline miR-552 & $2.97 \pm 2.72$ & $0.98 \pm 0.48$ \\
miR-142-3p & $3.64 \pm 3.41$ & $1.31 \pm 0.61$ \\
miR-139-3p & $0.81 \pm 0.67$ & $1.71 \pm 1.29$ \\
miR-133b & $0.10 \pm 0.26$ & $0.82 \pm 0.70$
\end{tabular}

HT-29 cells exposed to celecoxib

HT-29 cells exposed to DMSO

\begin{tabular}{lrr} 
miR-142-5p & $5.16 \pm 0.47$ & $1.4 \pm 0.26$ \\
miR-26a-1 $^{*}$ & $0.34 \pm 0.06$ & $0.95 \pm 0.09$ \\
\hline
\end{tabular}

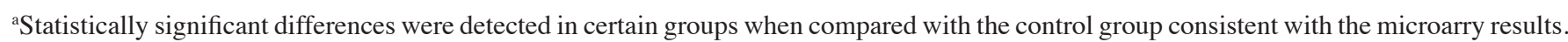
miRNA, microRNA; Q-RT-PCR, quantitative real-time polymerase chain reaction; SD, standard deviation; DMSO, dimethyl sulfoxide.

Table VI. Correlation between clinicopathological features and expression of four miRNAs.

\begin{tabular}{|c|c|c|c|c|c|}
\hline \multirow[b]{2}{*}{ Clinicopathological feature } & \multirow[b]{2}{*}{ No. of cases } & \multicolumn{4}{|c|}{ P-value ${ }^{a}$} \\
\hline & & $\operatorname{miR}-552$ & miR-142-3p & $\operatorname{miR}-133 b$ & miR-139-3p \\
\hline \multicolumn{6}{|l|}{ Age (years) } \\
\hline$>50$ & 21 & 0.642 & 0.193 & $0.028 *$ & 0.429 \\
\hline$\leq 50$ & 4 & & & & \\
\hline \multicolumn{6}{|l|}{ Gender } \\
\hline Male & 6 & 0.471 & 0.391 & 0.567 & 0.252 \\
\hline Female & 19 & & & & \\
\hline \multicolumn{6}{|l|}{ Histological grade } \\
\hline High & 1 & 0.755 & $0^{\mathrm{d}}$ & 0.68 & 0.303 \\
\hline Moderate & 19 & & & & \\
\hline Poor & 5 & & & & \\
\hline \multicolumn{6}{|l|}{ TNM stage ${ }^{b}$} \\
\hline I & 5 & $0.024^{\mathrm{d}}$ & 0.856 & 0.476 & $0.012^{\mathrm{d}}$ \\
\hline II & 8 & & & & \\
\hline III & 7 & & & & \\
\hline IV & 5 & & & & \\
\hline \multicolumn{6}{|l|}{ Lymph node involvement } \\
\hline$(+)$ & 12 & $0.004^{\mathrm{d}}$ & 0.728 & 0.255 & 0.057 \\
\hline$(-)$ & 13 & & & & \\
\hline \multicolumn{6}{|l|}{ Liver metastasis } \\
\hline$(+)$ & 5 & $0.016^{\mathrm{d}}$ & 0.882 & 0.466 & $0.001^{\mathrm{d}}$ \\
\hline$(-)$ & 20 & & & & \\
\hline \multicolumn{6}{|l|}{ Tumor size (cm) } \\
\hline$>5$ & 14 & 0.136 & 0.239 & 0.585 & 0.811 \\
\hline$\leq 5$ & 11 & & & & \\
\hline \multicolumn{6}{|l|}{ Depth of tumor invasion ${ }^{c}$} \\
\hline Mucosa & 6 & 0.268 & 0.542 & 0.614 & 0.178 \\
\hline Serosa & 19 & & & & \\
\hline
\end{tabular}

${ }^{\mathrm{a}}$ Correlation between clinicopathological features and expression of four miRNAs detected by ANOVA assay. ${ }^{\mathrm{b}} \mathrm{TNM}$ stage system formulated by AJCC/NCCN (2009) according to tumor size, lymph node involvement and distant metastasis. 'Invasive depth of the tumor (serosa, tumor invasion to the seroma; mucosa, tumor invasion to the mucosa). ${ }^{\mathrm{d}} \mathrm{P}<0.05$ was considered to indicate a statistically significant difference. miRNA, microRNA; ANOVA, analysis of variance. 
Table VII. Target genes of six selected deregulated miRNAs in the HT-29 cells treated with celecoxib.

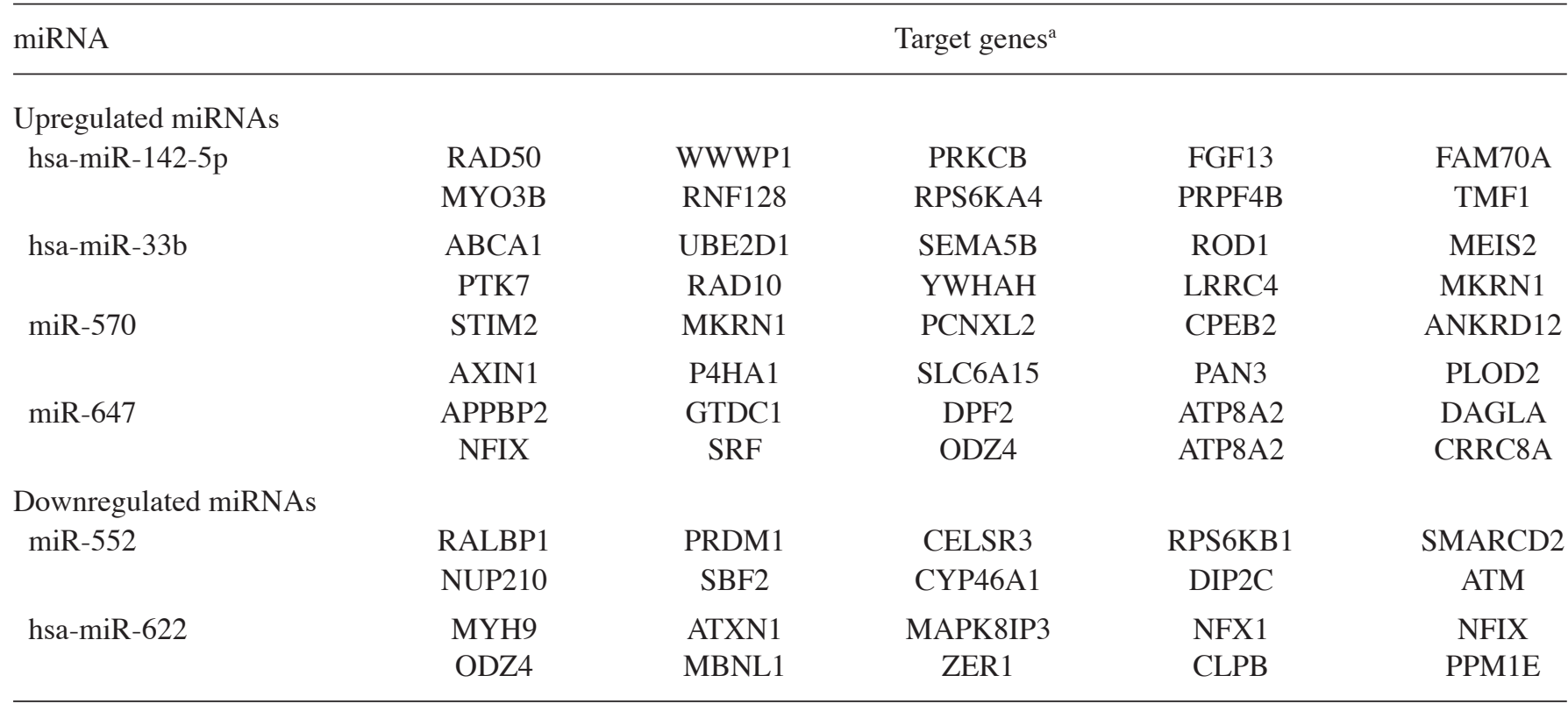

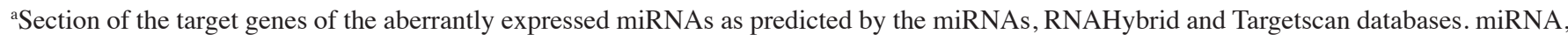
microRNA.

was observed in the cancer group compared with the normal tissue group (miR-552: cancer group, $2.97 \pm 2.72$ vs. normal group, $0.98 \pm 0.48$; miR-142-3p: cancer group, 3.64 \pm 3.41 vs. normal group, $1.31 \pm 0.61 ; \mathrm{P}<0.05)$, while miR-139-3p and miR-133b were downregulated (miR-139-3p: cancer group, $0.81 \pm 0.67$ vs. normal group, $1.71 \pm 1.29$; miR-133b: cancer group, $0.10 \pm 0.26$ vs. normal group, $0.82 \pm 0.70 ; \mathrm{P}<0.05)$. Similarly, miR-142-5p was found to be upregulated, while miR-26a-1* was downregulated in the HT-29 cells exposed to celecoxib (miR-142-5p: control group, $1.4 \pm 0.26$ vs. treated group, 5.16 \pm 0.47 ; miR-26a-1*: control group, $0.95 \pm 0.09$ vs . treated group $0.34 \pm 0.06)$. Q-RT-PCR results were found to be in accordance with the microarray analysis results.

Clinicopathological features and miRNA expression. Certain major miRNAs detected in the CRC through microarray analysis, including miR-552, miR-142-3p, miR-139-3p and miR-133b, that may have potential clinical significance were further analyzed according to the clinicopathological features of the patients, including age, gender, tumor size, lymph node and distance metastases, clinical stage and histological grade (Table VI). miR-552 was found to be correlated with TNM stage, lymph node and distance metastasis $(\mathrm{P}<0.05)$, but not with age, gender, size of tumor or histological grade. TNM stage and distant metastasis were associated with the differential expression of miR-139-3p, and histological grade disclosed aberrant expression of miR-142-3p. The other features did not demonstrate any association with the differentially expressed miRNAs.

miRNA target prediction, enrichment analysis and GeneGo pathway annotation based on HT-29 cell miRNA expression alteration. The computer and bioinformatic based predictions demonstrated that numerous mRNAs are able to be regulated by one miRNA and one mRNA simultaneously can been manipulated by several miRNAs, which indicates the complicated regulation network between miRNAs and their target mRNAs. Using six mature deregulated miRNAs, miR-142-5p, miR-33b, miR-570, miR-647, miR-622 and miR-552, we listed several of their target genes (Table VII) according to predictions from three databases. To overcome this, two functional analyses, enrichment and GeneGo pathway analysis, were then used to further detect the predicted genes targeted by the aberrant miRNAs in the HT-29 cell treated with celecoxib.

The high-enrichment analysis demonstrated that genes targeted by aberrant miRNAs following celecoxib intervention were involved in carbohydrate, protein and lipid metabolism, cell proliferation and regulation, apoptosis and cell cycle regulation, cell differentiation, cell adhesion regulation and angiogenesis. For example, target genes of miR-622 determined by the MetaCore database, were involved in cytoskeletal remodeling and cell adhesion-chemokine and adhesion pathways. However, target genes of miR-570 were involved in pathways for WNT5A-development signaling and WNT-development signaling (Fig. 1). Furthermore, GeneGo analysis revealed that almost 650 pathways, including metabolism, growth, differentiation, apoptosis and signal transduction, may participate in CRC carcinogenesis.

\section{Discussion}

In the present study, we identified 65 miRNAs that were deregulated in CRCs compared with normal tissues, of which, 35 miRNAs were upregulated and 30 miRNAs were downregulated. These results demonstrated that aberrant expression of miRNAs is involved in human carcinogenesis of the colorectum, and that expression of specific miRNAs could have the potential to select early-stage CRC. However, at 

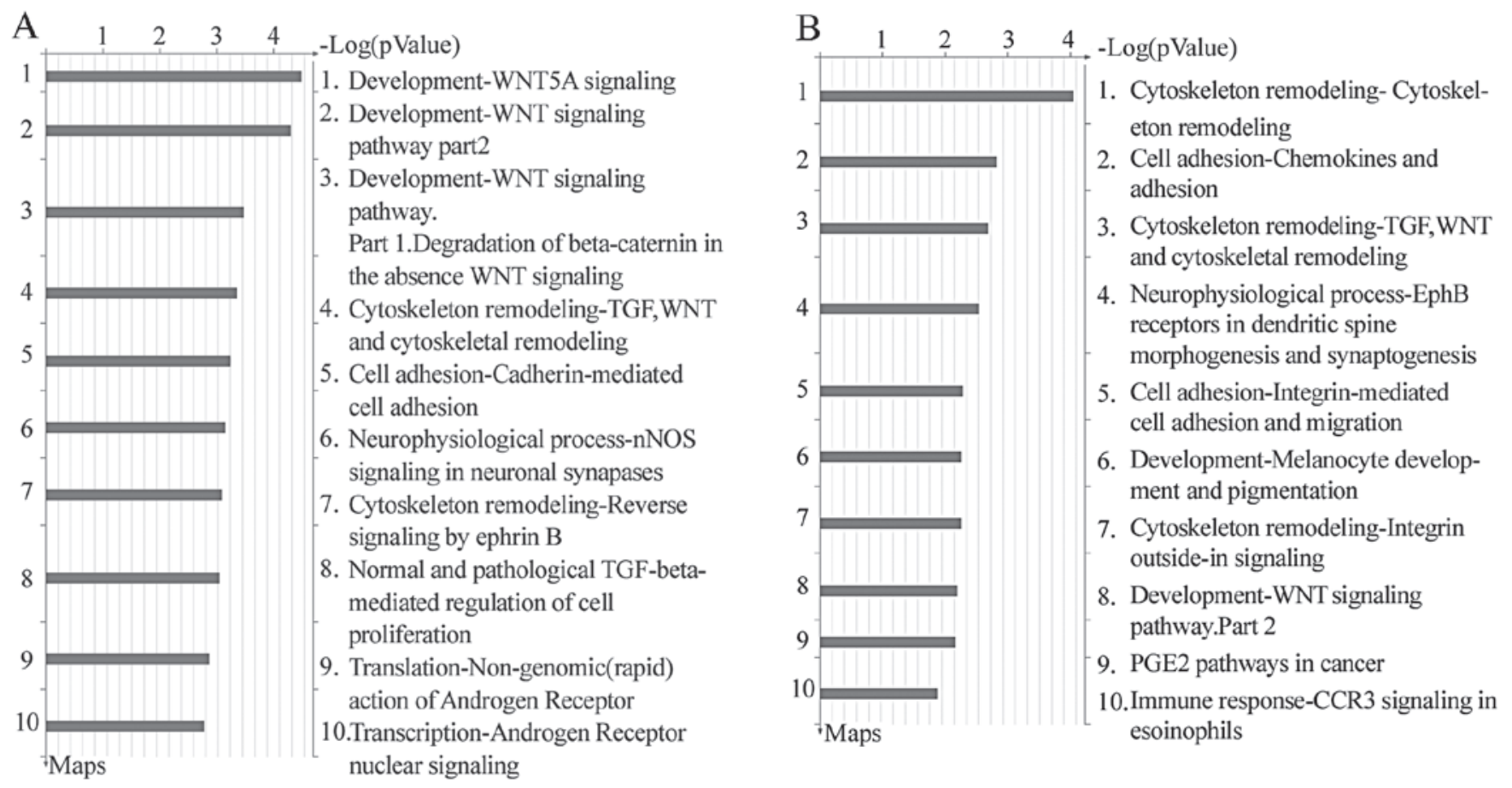

Figure 1. Enrichment analysis based on target genes of aberrant miRNAs in HT-29 cells treated with celecoxib. (A) The significant functional pathways targeted by selected upregulated miRNA, miR-570, and (B) selected downregulated miRNA, miR-622, respectively. The vertical axis indicates the pathway category, and the horizontal axis indicates the P-value. (original magnification, x300 DPI). miRNA, microRNA.

present, the expression profiles of miRNAs in previous studies focusing on aberrant miRNAs in CRCs were not identical and certain studies even revealed contrasting results (19-21). Although expression of 13 miRNAs, including miR-96, miR-31, miR-592, miR-135b, miR-183, miR-142-3p, miR-335, miR-32, miR-1, miR-9, miR-133a, miR-133b and miR-187, demonstrated no difference compared to previous studies, other aberrant miRNAs in our study were not consistent with previously reported results. We consider this to be due to differences in patient ethnicities, locations, genes, research methods and screening criteria. Therefore, this could be solved through perfecting the study methods and establishing unanimous screening standards in the near future.

Regarding the tissue specificity of miRNAs, previous studies have suggested that different miRNAs are likely to be deregulated in cancers of different cellular origins. For example, miR-21 and miR-155 were found to be uniquely overexpressed in pancreatic cancer compared to normal pancreas and chronic pancreatitis (9), while miR-125b and miR-145 were significantly deregulated in breast cancer (16). Moreover, due to the smaller number of miRNAs than the protein-coding genes, unique yet differential miRNA expression patterns may correlate more accurately with cancer type, stage and clinicopathological variables than gene profiling, which implied the specificity of the miRNAs as confirmed by Rosenfeld et $a l$ and $\mathrm{Lu}$ et $a l$ in their recent respective studies $(22,23)$. In our study, certain aberrantly expressed miRNAs in the cancer tissues compared with normal mucosa, including upregulated miRNAs, miR-549, miR-662, miR-142-5p, miR-431, miR-219-5p, miR-660, miR-21*, miR-452, miR-154*, miR-182*, miR-584, miR-494, miR-376c and miR-376a, and downregulated miRNAs, miR-29b-2*, miR-328, miR-363,
miR-20b, miR-597, miR-504 and miR-383, identified in CRCs were also found to be deregulated in other malignancies in previous studies, which did not display the specificity phenomenon. However, the other 13 miRNAs, miR-96, miR-31, miR-183, miR-135b, miR-142-3p, miR-335, miR-32, miR-9/9*, miR-1, miR-133a, miR-133b and miR-187, were found to be deregulated in CRC in our study and several previous studies targeting CRCs and have been seldom demonstrated in other cancer types (21,24-26), which might infer the tissue specificity of these aberrant miRNAs in human CRCs. Therefore, a small set of aberrant miRNAs mentioned above in our study not only distinguishing malignant tissues from normal tissue in the human colorectum, but also could be used to differentiate CRC tissues from the advanced cancer pool with unknown origin.

In addition to identifying the deregulated miRNAs in the CRC tissues, certain miRNAs which might have potential clinical significance as suggested by the functional analysis were found to be differentially expressed in distinct clinicopathological features. In this study, miR-552 was mostly overexpressed in lymph node and distant metastasis-positive colon cancers, suggesting that upregulation of this miRNA could be associated with a poorer prognosis. Furthermore, miR-139-3p, whose expression identified cancer tissue from normal tissue, was differentially expressed in cancers of different stages and grades. These findings indicate that deregulation of these two miRNAs are not only involved in the development of CRC, but also affect the molecular events in the progression of CRC. However, the comprehensive significance of all of these aberrant miRNAs in our study require further confirmation through further studies involving a greater number of clinical patients. 
Studies have revealed that aberrant miRNAs involved in tumorgenesis play a role as either an oncogene or a tumor suppressor depending on which genes they are targeting. Certain miRNAs, including let-7, miR-16, miR-10b, miR-125b and miR-145, were found to be downregulated and demonstrated a tumor-suppressor role in several types of cancers $(27,28)$, while others, including miR-17, miR-19, miR-21 and miR-155 may play a role as oncogenes through overexpression $(29,30)$. In this study, 65 aberrant miRNAs in CRCs as compared to normal tissues were observed to be oncogenes or tumor suppressors. Among these, 8 overexpressed miRNAs, including miR-96, miR-31, miR-592, miR-135b, miR-183, miR-142-3p, miR-335 and miR-32, may play roles as oncogenes and 5 downregulated miRNAs, including miR-1, miR-9, miR-133a, miR-133b and miR-187, may act as tumor suppressors; this was consistent with previous studies, therefore warranting further study.

In this study, we further found that following $48 \mathrm{~h}$ of exposure to celecoxib, the HT-29 cell growth was inhibited, accompanied with an alteration of the miRNA expression profile. The microarray results identified 28 aberrantly expressed miRNAs, of which 20 miRNAs were upregulated and 8 were downregulated. Therefore, we speculated that miRNA may be involved in the growth inhibitory role of celecoxib in CRC which elucidated additional mechanisms in the prevention and even treatment of CRC apart from inducing apoptosis and retarding the cell cycle. Four mature miRNAs, miR-33b, miR-30c-1, miR-647, miR-142-5p, have been reported to be associated with certain other cancer types, including endometrial, familial breast, non-small cell lung cancer and chronic lymphocytic leukemia, but CRC in previous studies (31-34). However, in our study, these four molecules were found to be upregulated in CRC cells treated with celecoxib. In addition, studies have revealed that colon cancer tumors and a variety of in vitro cultured tumor cell lines exhibited low expression of let7, while it was highly expressed in adjacent normal tissues (35). let7 targets a number of genes, including K-RAS, H-RAS, HMGA2, C-MYC and NF2, playing a negative regulatory role (36-39). Notably, upon intervention with celecoxib, expression of let-7i, a member of of the let-7 family, in HT-29 cells was significantly increased, indicating its role as a tumorsuppressor gene in our study.

In order to comprehensively understand the roles of the differentially expressed miRNAs during HT-29 cell growth inhibition folowing celecoxib intervention, the target genes and mechanism of regulation require further exploration. Through the use of three miRNA databases, we identified that a number of molecules involved in cell growth, apoptosis, metabolism and signal transduction, were target genes of these aberrantly expressed miRNAs, and each differentially expressed miRNA was able to regulate multiple target genes. Several genes, including PDGFRA, ROCK-2, EPHA3, AXIN1, CTNNB1, ACTN1, EIF4G1 and RASA3, previously involved in the pathogenesis of certain types of cancer were found to be targeted by miR-33b, miR-570 and miR-647 in our study, demonstrating their anti-tumor role in CRC.

Results from the GeneGo analysis revealed that target genes regulated by deregulated miRNAs could participate in several signaling pathways, including cytoskeletal remodeling, cell adhesion-chemokine and adhesion, neurophysiological process- receptor mediated axon growth repulsion, Wnt $/ \beta$-catenin pathway, cytoskeletal remodeling-role of PDGFs in cell migration, cytoskeletal remodeling-TGF, WNT and cytoskeletal remodeling involving several biological processes, including cell proliferation and regulation, apoptosis cell cycle regulation, cell differentiation, cell adhesion regulation and angiogenesis. Furthermore, following further enrichment analysis, one result which aroused great interest was that one of the downregulated miRNAs, miR-570, targeted genes CTNNB1, $\beta$-catenin, AXIN1 and FZD7. Therefore, we have reason to consider that miR-570 may modulate the WNT/ $\beta$-catenin pathway, which could then inhibit the growth of CRC cells. miR-570 may become a potential therapeutic target for CRC, however, further studies are required to determine this.

In conclusion, the results of the present study require validation by further investigation using larger CRC patient cohorts. However, despite its limitations, this study suggests that miRNAs affect the carcinogenesis of human CRC, and these cancer-associated miRNA signatures may become useful tools for identifying patients with early-stage CRC, and may thus improve the clinical outcome. miRNAs are involved in the celecoxib intervention process in CRC and may add new mechanism to its inhibitory role. The findings of the present study have expanded our knowledge of the molecular alterations involved in human $\mathrm{CRC}$ pathogenesis and the role of miRNAs in human cancer.

\section{Acknowledgements}

The authors thank the National Engineering Center for Biochip at Shanghai and Genminix Co. for providing technical assistance. This work is supported by the 333 Program of Science and Research Foundation of Jiangsu Province, China (no. 37RC2002037), the Medical Foundation of the Public Health Department of Jiangsu Province, China (no. H200959) and the Foundation of Science and Technology Burea of Suzhou, Jiangsu Province, China (no. YJS0915).

\section{References}

1. Lee HK, Choi YS, Park YA and Jeong S: Modulation of oncogenic transcription and alternative splicing by $\beta$-catenin and an RNA aptamer in colon cancer cells. Cancer Res 66: 10560-10566, 2006.

2. Casey G, Lindor NM, Papadopoulos N, Thibodeau SN, Moskow J, Steelman S, Buzin CH, Sommer SS, Collins CE, Butz M, Aronson M, Gallinger S, Barker MA, Young JP, Jass JR, Hopper JL, Diep A, Bapat B, Salem M, Seminara D, Haile R for the Colon Cancer Family Registry: Conversion analysis formutation detection in MLH1 and MSH2 in patients with colorectal cancer. JAMA 293: 799-809, 2005.

3. Hung KE and Chung DC: New insights into the molecular pathogenesis of colorectal cancer. Drug Discov Today Dis Mech 3: 439-445, 2006

4. Bartel DP: MicroRNAs: genomic, biogenesis, mechanism, and function. Cell 116: 281-297, 2004.

5. Gregory RI, Yan KP, Amuthan G, Chendrimada T, Doratotaj B, Cooch $\mathrm{N}$ and Shiekhattar R: The microprocessor complex mediates the genesis of microRNAs. Nature 432: 235-240, 2004.

6. Lewis BP, Burge CB and Bartel DP: Conserved seed pairing, often flanked by adenosines, indicates that thousands of human genes are microRNA targets. Cell 120: 15-20, 2005.

7. Calin GA, Dumitru CD, Shimizu M, Bichi R, Zupo S, Noch E, Aldler H, Rattan S, Keating M, Rai K, et al: Frequent deletions and down-regulation of microRNA genes miR15 and miR16 at 13 q14 in chronic lymphocytic leukemia. Proc Natl Acad Sci USA 99: 15524-15529, 2002. 
8. Takamizawa J, Konishi H, Yanagisawa K, Tomida S, Osada H, Endoh H, Harano T, Yatabe Y, Nagino M, Nimura Y, Mitsudomi T and Takahashi T: Reduced expression of the let-7 microRNAs in human lung cancers in association with shortened postoperative survival. Cancer Res 64: 3753-3756, 2004.

9. Bloomston M, Frankel WL, Petrocca F, Volinia S, Alder H, Hagan JP, Liu CG, Bhatt D, Taccioli C and Croce CM: MicroRNA expression patterns to differentiate pancreatic adenocarcinoma from normal pancreas and chronic pancreatitis. JAMA 297: 1901-1908, 2007.

10. Nagel R, Le Sage C, Diosdado B, van der Waal M, Oude Vrielink JA, Bolijn A, Meijer GA and Agami R: Regulation of the adenomatous polyposis coli gene by the miR-135 family in colorectal cancer. Cancer Res 68: 5795-5802, 2008.

11. Motoyama K, Inoue H, Takatsuno Y, Tanaka F, Mimori K, Uetake H, Sugihara K and Mori M: Over- and under-expressed microRNAs in human colorectal cancer. Int J Oncol 34: 1069-1075, 2009.

12. Valeri N, Croce CM and Fabbri M: Pathogenetic and clinical relevance of microRNAs in colorectal cancer. Cancer Genomics Proteomics 6: 195-204, 2009.

13. Toyoshima T, Kamijo R, Takizawa K, Sumitani K, Ito D and Nagumo M: Inhibitor of cyclooxygenase-2 induces cell-cycle arrest in the epithelial cancer cell line via up-regulation of cyclin dependent kinase inhibitor p21. Br J Cancer 6: 1150-1156, 2002.

14. Johnson AJ, Hsu AL, Lin HP, Song X and Chen CS: The cyclooxygenase- 2 inhibitor celecoxib perturbs intracellular calcium by inhibiting endoplasmic reticulum $\mathrm{Ca}^{2+}$-ATPases: a plausible link with its antitumor effect and cardiovascular risks. Biochem J 366: 831-837, 2002

15. Zhu J, Huang JW, Tseng PH, Yang YT, Fowble J, Shiau CW, Shaw Y, Kulp SK and Chen CS: From the cyclooxygenase-2 inhibitor celecoxib to a novel class of 3-phosphoinositidedependent protein kinase-1 inhibitors. Cancer Res 64: 4309- 4318 , 2004.

16. Iorio MV, Manuela F, Liu CG, Angelo V, Spizzo R, Sabbioni S, Magri E, Pedriali M, Fabbri M, Campiglio M, Ménard S, Palazzo JP, Rosenberg A, Musiani P, Volinia S, Nenci I, Calin GA, Querzoli P, Negrini M and Croce CM: MicroRNA gene expression deregulation in human breast cancer. Cancer Res 65: 7065-7070, 2005

17. Feber A, Xi L, Luketich JD, Pennathur A, Landreneau RJ, Wu M, Swanson SJ, Godfrey TE and Litle VR: MicroRNA expression profiles of esophageal cancer. J Thorac Cardiovasc Surg 135: 255-260, 2008.

18. Griffiths-Jones S, Grocock RJ, van Dongen S, Bateman A and Enright AJ: miRBase: microNRA sequences, target and gene nomenclature. Nucleic Acids Res 34: 140-144, 2006.

19. Michael MZ, O'Connor SM, van Holst Pellekaan NG, Young GP and James RJ: Reduced accumulation of specific microRNAs in colorectal neoplasia. Mol Cancer Res 1: 882-891, 2003.

20. Schetter AJ, Leung SY, Sohn JJ, Zanetti KA, Bowman ED, Yanaihara N, Yuen ST, Chan TL, Kwong DLW, Au GKH, et al: MicroRNA expression profiles associated with prognosis and therapeutic outcome in colon adenocarcinoma. JAMA 299: 425-436, 2008.

21. Sarver AL, French AJ, Borralho PM, Thayanithy V, Oberg AL, Bergemann TL, Gupta M, O'Sullivan MG, Matise I, Dupuy AJ, et al: Human colon cancer profiles show differential microRNA expression depending on mismatch repair status and are characteristic of undifferentiated proliferative states. BMC Cancer 9: 401-406, 2009

22. Rosenfeld N, Aharonov R, Meiri E, Rosenwald S, Spector Y, Zepeniuk M, Benjamin H, Shabes N, Tabak S, Levy A, et al: MicroRNAs accurately identify cancer tissue origin. Nat Biotechnol 26: 462-469, 2008

23. Lu J, Getz G, Miska EA, Alvarez-Saavedra E, Lamb J, Peck D, Sweet-Cordero A, Ebert BL, Mak RH, Ferrando AA, et al: MicroRNA expression profiles classify human cancers. Nature 435: 834-838, 2005
24. Bandres E, Cubedo E, Agirre X, Malumbres R, Zarate R, Ramirez N, Abajo A, Navarro A, Moreno I, Monzo M and Garcia-Foncillas J: Identification by real-time PCR of 13 mature microRNAs differentially expressed in colorectal cancer and non-tumoral tissues. Mol Cancer 5: 29, 2006.

25. Bandres E, Agirre X, Bitarte N, Ramirez N, Zarate R, Roman-Gomez J, Prosper F and Garcia-Foncillas J: Epigenetic regulation of microRNA expression in colorectal cancer. Int J Cancer 125: 2737-2743, 2009.

26. Schepeler T, Reinert JT, Ostenfeld MS, Christensen LL, Silahtaroglu AN, Dyrskjøt L, Wiuf C, Sørensen FJ, Kruhøffer M, Laurberg S, et al: Diagnostic and prognostic microRNAs in stage II colon cancer. Cancer Res 68: 6416-6124, 2008.

27. Johnson SM, Grosshans H, Shingara J, Byrom M, Jarvis R, Cheng A, Labourier E, Reinert KL, Brown D and Slack FJ: RAS is regulated by the let-7 microRNA family. Cell 120: 635-647, 2005.

28. Cimmino A, Calin GA, Fabbri M, Iorio MV, Ferracin M, Shimizu M, Wojcik SE, Aqeilan RI, Zupo S, Dono M, et al: miR-15 and miR-16 induce apoptosis by targeting BCL2. Proc Natl Acad Sci USA 102: 13944-13949, 2005.

29. He L, Thomson JM, Hemann MT, Hernando-Mong E, Mu D, Goodson S, Powers S, Cordon-Cardo C, Lowe SW, Hannon GJ and Hammond SM: A microRNA polyistron as a potential human oncogene. Nature 435: 828-833, 2005

30. Huang GL, Zhang XH, Guo GL, Huang KT, Yang KY, Shen X, You J and Hu XQ: Clinical significance of miR-21 expression in breast cancer: SYBR-Green I-based real-time RT-PCR study of invasive ductal carcinoma. Oncol Rep 21: 673-679, 2009.

31. Calin GA, Sevignani C, Ferrai JG, Hyslop T, Noch E, Yendamuri S, Shimizu M, Rattan S, Bullrich F, Negrini M and Croce CM: Human microRNA genes are frequently located at fragile sites and genomic regions involved in cancers. Proc Nat Acad Sci USA 101: 2999-3004, 2004.

32. Shen J, Ambrosone CB and Zhao H: Novel genetic variants in microRNA genes and familial breast cancer. Int J Cancer 124: 1178-1182, 2009.

33. Patnaik SK, Kannisto E, Knudsen S and Yendamuri S: Evaluation of microRNA expression profiles that may predict recurrence of localized stage I non-small cell lung cancer after surgical resection. Cancer Res 70: 36-45, 2010.

34. Zanette DL, Rivadavia F, Jacoby S, Barbuzano FG, Proto-Siqueira R, Silva WA Jr, Falcao RP and Zago MA: MiRNA expression profiles in chronic lymphocytic and acute lymphocytic leukemia. Braz J Med Bio Res 40: 1435-1440, 2007.

35. Bussing I, Slack FJ and Grosshans H: Let-7 microRNAs in development stem cells and cancer. Trends Mol Med 14: 400-409, 2008.

36. Johnson SM, Grosshans H, Shingara J, Byrom M, Jarvis R, Cheng A, Labourier E, Reinert KL, Brown D and Slack FJ: RAS is regulated by the let-7 microRNA family. Cell 120: 635-647, 2005.

37. Lee YS and Dutta A: The tumor suppressor microRNA let-7 represses the HMGA2 oncogene. Genes Dev 21: 1025-1030, 2007.

38. Sampson VB, Rong NH, Han J, Yang Q, Aris V, Soteropoulos P, Petrelli NJ, Dunn SP and Krueger LJ: MicroRNA let-7a down regulates MYC and reverts MYC-induced growth in Burkitt lymphoma cells. Cancer Res 67: 9762-9770, 2007.

39. Meng F, Henson R, Iinuma M, Smith H, Ueno Y and Patel T: The microRNA let-7a modulates interleukin-6 dependent STAT-3 survival signaling in malignant human cholangiocytes. J Biol Chem 282: 8256-8264, 2007. 